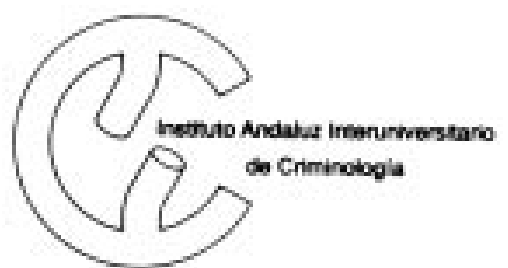

Director: Per Stangeland

Coordinadora: Elisa García España

Publicado por la Sección de Málaga del IAIC

Facultad de Derecho, Universidad de Málaga

Campus de Teatinos, 29071 MALAGA.

\title{
LENTITUD DE LOS PROCESOS PENALES EN MALAGA.
}

Autores:
Ana $\mathrm{M}^{\mathrm{a}}$ López Luque
Dolores C. López Rubio
Antonia Rodríguez Avilés
$\mathrm{M}^{\circ}$ Victoria Rosas Lozano
Luís Torres Martín
José María Vico Aranda

Este artículo presenta un análisis de las causas internas del retraso que sufren los procedimientos penales en nuestra provincia, entendiendo por tales causas las que van referidas al propio funcionamiento y estructura de los Juzgados, prescindiendo de las causas externas ogenerales que afectan también a otras Administraciones.

\section{CASOREAL}

Si examinamos un supuesto real de procedimientopenalexistente en uno de los juzgados de Ins-

\section{METODOS}

Este artículo incluye algunos de los puntos desarrollados en el trabajo elaborado por un grupo de alumnos de segundo curso de Criminología, tituladoAdministración de Justicia Penal en Málaga. Estudio Criminológico, que pretende realizar un somero acercamiento a dicha Administración, analizando sus deficiencias, su compleja estructura y funcionamiento.La metodología utilizada ha sido la observación participante y el análisis documental.

\section{PROCEDIMIENTO ABREVIADO XXX/88}

25/03/88 Incoación de las diligencias previas en Málaga

08/04/88 Declaración del perjudicado

22/04/88 Personación de la acusación particular

13/06/88 Declaración del perjudicado

29/06/88 El juzgado de Málaga se comunica con el de Fuengirola mediante exhorto para citar al implicado

11/07/88 El exhorto se devuelve sin cumplimentar al no encontrarse al implicado

11/07/88 El Juzgado de Málaga insiste y manda un nuevo exhorto a Fuengirola

29/09/88 Al no ser localizado se manda un oficio a la policía para que lo localice

03/04/89 Se recuerda el oficio a la policía

23/05/89 Una vez localizado se dicta una providencia acordando la citación del implicado

24/05/89 Al no acudir el implicado se manda oficio a la policía para que lo cite

21/08/89 Solicitud de antecedentes penales

14/12/89 Recordatorio de antecedentes penales

26/03/90 Con los antecedentes penales y conociendo la pena que le corresponde en abstracto se incoa el procedimiento abreviado

21/11/90 Traslado a la acusación particular para calificación

11/02/91 Auto de apertura de la fase de juicio oral

21/02/91 Orden de busca y captura

15/01/92 Se recuerda la busca y captura

17/02/92 Declaración de rebeldía y se sobresee provisionalmente hasta que aparezca el implicado

06/10/92 Notificación a la acusación particular del sobreseimiento

07/03/93 Aparecido el implicado se manda un nuevo exhorto a Fuengirola para tomarle declaración

17/03/93 Auto de prisión

18/03/93 Oficio solicitando expulsión por tratarse de un extranjero

12/04/93 Reiteración de la solicitud de expulsión

03/05/93 La acusación particular recurre

08/06/93 Auto estimando el recurso

13/11/93 Se acuerda notificación a otro acusado

18/04/94 Orden de busca y captura del nuevo acusado y paralización del expediente hasta su aparición

\section{$\begin{array}{lllllll}\text { Boletín Criminológico } & \text { N } & 3 & \text { Septienbre } & 1994 & \text { Página } & 1\end{array}$}


trucción de Málaga, cambiando algunos detalles para evitar la identificación del caso, podemos apreciar las dificultades y dilaciones expuestas. No obstante, hay que advertir que el ejemploplanteado, si bien es ilustrativodela lentitud de la Administración de Justicia, no es un caso típico ya que en la actualidad la media de tiempo empleado en la instrucción de causas se ha reducido bastante en lo que a delitos comunes se refiere (ejem:robos, hurtos, etc), viniendo atardartoda la tramitación del expedientehastasu resolución ( estoes, desde la incoación del mismohasta la sentencia) alrededor de un año. En las causas por delitos más graves oen las que haya varios acusados omuchos testigos, tanto la tramitación como la celebración del juicio suele plantear más problemas y, por tanto, la resolución se demora más. Así, el caso propuestoen el cuadroanteriorconstituyeun ejemploespecial porque en él confluyen muchas de las causas que provocan el retraso de un procedimiento, desde la duplicidad de las actuaciones (comolibramiento de exhor-tosy oficios, y los respectivos recordatorios de exhortos y oficios...) hasta la orden de busca y captura y el archivo del procedimiento (por encontrarse el acusado en paradero desconocido), la reapertura del mismo (por haber sido halladoel acusado), la solicitud de expulsión y su reiteración (el acusado es extranjero) o un recurso interpuesto por la acusación particular(contra el autoque acuerda la expulsión). Con todo elloresultaque, transcurridos seis años desde la incoación del procedimiento, este caso aún noestá resuelto, ni siquieraremitido al Juzgado de lo Penal que habrá de juzgarlo.

Lainsuficiencia de lainfraestructura administrativa-o quizás la mala gestión-, entendiéndose como tal el conjunto de medios materiales y personales puestos a disposición de la Administración de Justicia, es una de las mayores causas dela"crisis" de la misma.

\section{ELEDIFICIO}

A pesar de que los Juzgados del orden penal en Málaga (excepto el de Menores), es decir, los de Instrucción, de lo Penal y las Salas de la Audiencia, están ubicados en el Palacio de Justicia Miramar, éste no deja de ser un edificio con concepciones decimonónicas basado más en característicasdeorna-mentación y boatoque de funcionalidad. La falta de espacio con la que nació imposibilita una futura ampliación del mismo. Además, los juzgados presentan una compleja distribución a laque se accede por una laberíntica red de pasillos, escaleras y ascensores, mal señalizados, donde no es de extrañar ver a personas perdidas o quejándose de no encontrar el lugar a donde han de acudir.

Por otra parte, los locales que albergan los Juzgados continúan siendo inadecuados, no adaptados a las necesidades reales ni legales. A título de ejemplo, es normal veralos testigos que han de declararenjuicio y que en principio deberían estar incomunicados entre sí, comentando el caso antes de entrar a la sala de vistas en la puerta de la misma. Las secciones donde se desarrolla la actividad diaria de los Juzgados suelen ser reducidase incómodas, dándose situaciones tales como que mientras un funcionario teclea algún escrito, hay otroa sulado que estánotificando una sentencia, un tercero que habla por teléfono y un cuarto que recibe declaración en presencia de todos cuantos se encuentran allí en ese momento.

\section{EXIGENCIASPROCESALES}

La existencia, por otro lado,

\section{Título de Experto en Criminología}

El Instituto Andaluz Interuniversitario de Criminología de la Universidad de Málaga imparte estudios de Experto Universitario en Criminología cuya duración es de tres años.

Los interesados deben haber realizado el primer ciclo de estudios universitarios o bien, teniendo aprobada la selectividad o equivalente, pertenecer a las Cuerpos y Fuerzas de Seguridad del Estado, Guardia Civil, Policía Local, Administración de Justicia, Instituciones Penitenciarias o ser auxiliares de investigador privado.

Todo tipo de información sobre el contenido y estructura del Título y las condiciones de ingreso se puede obtener en la Secretaría del Instituto (Facultad de Derecho de la Universidad de Málaga) teléfono 2132325 .
Boletín Criminológico
N 3
Septienbre
1994
Página 2 
de Juzgados de lo Penal sólo en Málaga capital contribuye a que éstos estén colapsados y a que los procedimientos sedilaten; especialmente aquellos que llegan incompletos o con algún defecto procesal ya que han de ser deEl proceso penal hace un sigl Ya en la Exposición de Motivos de la Ley de Enjuiciamiento Criminal de 1.882, aún vigente, el entonces Ministro de Gracia y Justicia D. Manuel Alonso Martínez, se lamentaba de extremos tales como la omnipotencia absoluta de los jueces, la tardanza de los procedimientos, la necesidad de acabar con las prácticas abusivas y atentatorias de los derechos individuales, la verdad de artificio en que acababa constituyéndose el sumario...

"Los Jueces de primera instancia..delegan frecuentemente la práctica de muchas diligencias en el Escribano, quien, a solas con el procesado y los testigos, no siempre interpreta bien el pensamiento, ni retrata con perfecta fidelidad las impresiones de cada uno.."

"... No es raro que un sumario dure ocho o más años, y es frecuente que no dure menos de dos, prolongándose en ocasiones por todb este tiempo la prisión preventiva de los acusados..."

"Educados los españoles durante siglos en el procedimiento escrito, secreto inquisitorial, lejos de haber adquirido confianza en la Justicia....se han desviado cada vez más de los Tribunales, mirando con lamentable recelo a los Magistrados, Jueces, Escribanos y Alguaciles, y repugnando figurar como testigos en el proceso".

Alonso Martínez: Exposición de motivos de la Ley de Enjuiciamiento Criminal de 14 de septiembre de 1882.

$\begin{array}{lllll}\text { Boletín Criminológico N } & 3 & \text { Septienbre } & 1994 & \text { Página } 3\end{array}$

vueltos al Juzgado instructor que los remitió, para su subsanación.

\section{LOS MEDIOS DE TRA-} BAJO

Los medios de trabajo que se emplean en los Juzgados son primarios: máquinas de escribirmanuales en la mayoría de los casos; donde hay ordenadores son utilizados casi de forma exclusiva para tratamiento de textos; los Juzgados funcionan comoínsulas aisladas entre sí, sin que exista una red de ordenadores que los comunique y coordine entre ellos; noexiste un sistemacentralizadode información al públiconi a profesionales del Derecho, sino personalizado, loque supone que el funcionario que tramita un expediente es el único que generalmente es capaz de localizarlo e informar sobre él; los tradicionales medios de comunicaciónutilizadosparacitaciones, requerimientos, comunicaciones a otros Juzgados, etc (a través de cartas y exhortos que, a menudo, hay que recordar una o varias veces), nohacen sinodemorar inútilmente el desarrollo del procedimiento; el sistemade archivos es el mismo de hace siglos, noexistiendoun archivo centralizadoy ordenadosistemáticamente; perdurael sistema de unión de expedientes por medio de cuerda floja (expedientes cosidos), que no es sino unareminiscenciahistórica.

La estructura de la oficina judicial permanece anquilosada, con las únicas modificaciones originadas por la incorporación de la informática y por la creación de algunos servicios comunes. La mezcla de las actividades de ca- rácter administrativo con las de carácter jurisdiccional afecta negativamentealfuncionamientode los servicios.

\section{MODELO DE TRABAJO}

Se carece de un modelo unificado de trabajo común a toda la oficina judicial.Elloda como resultado la existencia de casi tantos modelos como órganos judiciales y situaciones distintas de eficacia o de carga de trabajo resuelta por año.Laeficacia de la oficinajudicial viene determinada también por la disposición particulardelpersonalqueintegracada órgano, produciéndose en base a ella situaciones muy diferentes entre los Juzgados de un mismo orden jurisdiccional y entre distintos órdenes en una mismaciudad, creándose agravios comparativos que juegan en contra del personal que más se esfuerza, que suele ser al que más trabajo se le asigna.

\section{DISTRIBUCION DE FUNCIONES}

El actual sistema de distribución de funciones entre el personal queintegra un Juzgado suele desconcertar. A menudo se confunde la labor de los auxiliaresconla de los oficiales, pues ambos realizan tareas administrativas, diferenciándose en la práctica una categoría profesional de otra sólo en la nómina. El sistema de habilitaciones y sustituciones que prevé la Ley Orgánica del Poder Judicial viene siendoutilizadopor los Secretarios en más casos de los quedeberían, delegandocon- 
tinuamente sus funciones en oficiales que realizanun trabajoque en principio no les correspondey por el que no perciben compensación económica alguna. Ensentidoestricto, un oficial del Juzgado notiene la obligación de tomar declaraciones, ni de preparar pruebas, ni de decidir si da la razóna unou otroletrado, aunque ésto sea la práctica habitual.

La dación de cuenta, función atribuida al Secretario Judicial por la referida Ley y consistente en la información oral por

\section{SUGERENCIAS}

Existe una gran necesidad de reformar las leyes procesales, de mejorar los recursos humanos y materiales, de despenalizar determinadas conductas y de replantearse las competencias del Ministerio Fiscal y de los Juzgados de Instrucción.

Estos temas no han podido ser abarcados en este Boletín, sin embargo, presentamos algunas sugerencias concretas a lo especificado en este artículo:

- Un edificio de nueva planta más funcional.

- Mejor distribución geográfica de los órganos judiciales.

- Adecuación de la estructura y funcionamiento de la oficina ju dicial a la realidad social.

- Incremento de responsabilidad y toma de decisiones por parte de los funcionarios que trami tan el expediente, siempre que no afecte a derechos fundamen tales. parte de éste al Magistrado de la presentación de escritos y documentos el mismo día o al siguiente hábil, odel transcurso de plazos procesales $\mathrm{u}$ otras diligencias, asícomolafepúblicajudicial cuyo depositario es igual y exclusivamente el Secretario Judicial, único competente para decirque loque expresan las actuaciones judiciales es cierto, por lo cual todas ellas deben practicarse en su presencia, resultan muy difíciles.Evidentemente, dichofuncionario no puede estar presente en todas las que se realizan a la vezen un Juzgado. Porejemplo, no puede estar presente en una declaración, en una notificación y en un requerimiento, tres diligencias que suelen practicarse simultáneamente y a diarioen un mismo Juzgado en sus diferentes dependencias. De ahí que se produzca un formulismo retóricoy unacontinuafalsedad documental asumidos por los diferentes colectivos que integran la Administración de Justicia.

\section{DIFICULTAD DE ACCESO PARA LOS CIUDADANOS}

Otro problema con el que nos encontramos es el de la dificultad de acceso de los ciudadanos a la Justicia, entendida como la capacidad para acudir a los Tribunales y obtener de ellos una solución a susconflictos. El coste, en dineroy en tiempo, que supone recurrir a la víajudicial hace que cada vez más los ciudadanos sean reacios y desconfiados de la acción de la Justicia.

\section{fe de erratas}

En el Boletín nº 2 , en la tabla de la página 3 , hay un error en la suma total de diligencias procedentes de la Policía Nacional. En vez de sumar 670, el total es de 700. El porcentaje correspondiente refleja ésta última cifra.

El Boletín criminológico da un breve resumen de trabajos de investigación llevados a cabo en la Sección de Málaga del Instituto AndaluzInteruniversitario de Criminología. Seedita un boletín cada mes y la subscripción es gratuita.

Quierorecibirelboletín criminológico

Nombre

Cargo

Dirección
Boletín Criminológico
$\mathrm{N} 3$
Septienbre
1994
Página 4 